\title{
O Controle de Preço de Medicamentos
}

\author{
DRUGS PRICE CONTROL
}

Erica Maluf(*)

\section{RESUMO}

Este trabalho tem como objetivo analisar o controle de preços ao qual os medicamentos estão sujeitos no Brasil desde 2003. O período da pesquisa foi de junho de 2003 a dezembro de 2005. Aborda-se uma retrospectiva histórica contemplando diversas regulamentações, passando por Constituições estrangeiras e nacionais e a evolução do tema. Trata-se, ainda, da questão da saúde, que tem um tratamento diferenciado entre os serviços públicos, porque pode ser explorada pelos particulares sem a necessidade de concessão estatal. Além disso, foram feitas sucintas considerações sobre as chamadas falhas de concorrência no mercado de medicamentos para demonstrar o congelamento de preços dos medicamentos no Brasil. Foram analisadas algumas normas que estabelecem o controle de preços de medicamentos, especificamente no que refere a sua validade perante a Constituição Federal, bem como a legalidade dos atos que são praticados pela Câmara de Regulação do Mercado de Medicamentos - CMED além de terem sido comparadas as regulamentações em face da Constituição Federal. A conclusão leva a considerar a interferência no controle de preços inconstitucional, em decorrência de sua ineficácia comprovada; contudo, válida em relação aos outros dispositivos de regulação do mercado de medicamentos e, nesse aspecto, defende-se a necessidade de uma reforma regulatória, visto que há certa inconsistência entre o atual quadro regulatório e o cenário de estabilidade econômica, num horizonte de crescimento e desenvolvimento.

\section{Palavras-chave:}

Agência Nacional de Vigilância Sanitária; Câmara de Regulação do Mercado de Medicamento; Controle de Preço; Medicamento.

(*) Farmacêutica Industrial, especialista em Marketing pela Escola Superior de Propaganda e Marketing, especialista em Direito Sanitário, pela Universidade de São Paulo. São Paulo/SP-Brasil. E-mail: e_maluf@ hotmail.com. Recebido em 23.03.10. Aprovado em 25.08.10. 


\begin{abstract}
This work intends to analyze the price control of medicines, since 2003, in Brazil, considering June 2003 to December 2005. It carries out a historical retrospective contemplating regulations, through foreign and national Constitutions, and the evolution of the theme. It approaches health, which has a differential treatment between public services, because it can be exploited by individuals without the need for state grant. Moreover, there are brief considerations on so-called failures of competition in the drug market to demonstrate the freezing of prices of medicines in Brazil. This work analyzes some standards that set the price control of medicines, specifically related to its validity in the Federal Constitution and the legality of the acts that are practiced by the Brazilian Board of Market Regulation of Medicines. It also compares regulations facing Federal Constitution. It concludes that the interference at price control is unconstitucional due to its proven ineffectiveness. However, it is valid due to other devices to regulate the drug market and, because of this aspect, this work stands for the need of a regulatory reform, since there are some inconsistency between the current regulatory framework and the scenario of economic stability, a horizon of growth and development.
\end{abstract}

\title{
Keywords:
}

Brazilian National Drugs Price Control Chamber; Brazilian National Health Surveillance Agency; Drug; Price Control.

\section{INTRODUÇÃO}

O intuito deste estudo foi analisar a interferência a que os preços dos medicamentos estão sujeitos no Brasil no período de junho de 2003 a dezembro de 2005, sob o enfoque da constitucionalidade deste controle e a forma como é realizado.

O acesso aos medicamentos, produtos e serviços de saúde é garantido pela Constituição Federal de 1988 - art. 196 e pela Lei Orgânica da Saúde (LOS - Lei n. 8.080/90 e Lei n. 8.142/90), devendo ser promovido pela União, Estados e Municípios, em competência concorrente.

Podemos afirmar que o mundo se encontra em um sistema dinâmico, em que a liberdade dos agentes econômicos está condicionada à geração de bem-estar para a sociedade.

Para conter o aumento de preço no setor farmacêutico, o Governo Federal implantou um controle de preços legislando, inicialmente, por meio 
de Medida Provisória, posteriormente convertida em Lei e regulamentada por resoluções, que, ao contrário do que se esperava, refletiu na carência de medicamentos, mais observado, ainda nas camadas de baixa renda da população.

Fizemos, sucintas considerações sobre as chamadas falhas de concorrência no mercado de medicamentos, com o objetivo de demonstrar os efeitos do congelamento de preços de medicamentos no Brasil e, após essas considerações, será analisada a Lei n. 10.742/03 que estabelece o controle de preços de medicamentos, especificamente no que se refere a sua eficácia perante a Constituição Federal, bem como a legalidade dos atos que são praticados pela Câmara de Regulação do Mercado de Medicamentos - CMED, além de destacar a competência da CMED e da Agência de Vigilância Sanitária - ANVISA com relação ao tema em questão(1).

\section{MATERIAL E MÉTODOS}

A CMED foi criada em 2003 por meio, do Decreto n. 4.766 que regulamentou a sua criação, competências e o funcionamento da Câmara, todavia foi pela Medida Provisória n. 123, de 26 de junho de 2003 e pela Lei n. 10.742, de 6 de outubro de 2003, onde ambas alteram artigos da Lei $n$. 6.360 , de 23 de setembro de 1976, que foram definidos os objetivos de regulação para o setor farmacêutico(2).

Destacamos que de acordo com as regras estabelecidas na legislação acima, o ajuste de preços só poderá ocorrer a cada doze meses, a partir de março de 2004 e os reajustes serão limitados a um teto de preços que será definido levando em consideração o Índice Nacional de Preços ao Consumidor Amplo - IPCA, fornecido pelo Instituto Brasileiro de Geografia e Estatística - IBGE, mais um fator de produtividade e um fator de ajuste de preços relativos intrassetor e entre setores, ambos expressos em percentuais. "Não dá para trabalhar todos os medicamentos e todo o setor da mesma forma", esclareceu o Secretário de Acompanhamento Econômico do Ministério da Justiça, Daniel Goldberg(3).

Podemos dizer que a nova política de regulação do mercado farmacêutico pretendeu aumentar a concorrência, fortalecer o poder de compra do consumidor e estabelecer regras objetivas para nortear os ajustes

(1) GRAU, Robert E. A Ordem Econômica na Constituição de 1988. 8. ed. São Paulo: Malheiros Ed., 2003. p. 99.

(2) SANCHEZ, C. G. Aspectos da relação entre Estado e iniciativa privada: enfoque constitucional 1999. Dissertação (Mestrado em Direito Constitucional) - Faculdade de Direito, Pontifícia Universidade Católica, São Paulo, 1999. p. 463-464.

(3) Citação de 27 de junho de 2003 onde Governo anuncia a política de regulação do mercado farmacêutico - Assessoria de impressa do Ministério da Saúde. 
e correções de preços para os medicamentos, onde também seriam definidos os preços de referência para a aquisição de medicamentos que integram as listas de produtos distribuídos à população pelo Sistema Único de Saúde SUS, entretanto, não foi o que se observou.

É de extrema importância analisar a Lei n. 10.742/03, pois assim podemos verificar que as competências da CMED, que são: a) definir diretrizes e procedimentos relativos à regulação econômica do mercado de medicamentos; b) estabelecer critérios para fixação e ajuste de preços de medicamentos; c) definir claramente os critérios para o estabelecimento dos preços dos produtos novos e novas apresentações de medicamentos, utilizando as informações fornecidas à ANVISA por ocasião do pedido de registro dos produtos novos ou novas apresentações; d) zelar pela proteção dos interesses do consumidor de medicamentos; e) decidir sobre a aplicação de penalidades previstas nesta Lei e relativamente ao mercado de medicamentos, aquelas previstas na Lei n. 8.078, de 11 de setembro de 1990 (Código de Defesa do Consumidor), sem prejuízo das competências dos demais órgãos do Sistema Nacional de Defesa do Consumidor entre outras atividades afins.

Como o foco deste trabalho é a retrospectiva do controle de preços, foi feito um histórico das regulamentações de preços no período entre 2003 a 2005, destacando que a Lei n. 6.360/76 por meio do seu art. 16 já definia algumas regras.

\section{3}

Resolução n. 1, de 27 de junho de 2003 - Estabeleceu os critérios de definição de preços iniciais de novas apresentações e produtos novos de que tratam 0 art. $7^{\circ}$ da Medida Provisória n. 123, de 26 de julho de 2003. (Revogada pela Resolução CMED n. 2, de 5 de março de 2004);

Resolução n. 2, de 27 de junho de 2003 - Liberou dos critérios de estabelecimento ou ajuste de preços, de que tratava o inciso IV do art. 6으 da Medida Provisória no 123, de 26 de junho de 2003, os medicamentos listados no anexo à presente Resolução;

Resolução n. 3, de 29 de julho de 2003 - Aprovou o Regimento Interno da Câmara de Regulação do Mercado de Medicamentos. (Alterada pela Resolução CMED n. 3, de 15 de junho de 2005, publicada no DOU 7 de outubro de 2005); e

Resolução n. 5, de 9 de outubro de 2003 - Liberou dos critérios de estabelecimento ou ajuste de preços, de que tratava o inciso IV do art. $6^{\circ}$ da Lei n. 10.742, de 6 de outubro de 2003, os medicamentos homeopáticos.

\section{4}

Resolução n. 2, de 5 de março de 2004 - Aprovou, na forma de anexo a esta Resolução, os critérios para definição de preços de produtos novos e 
novas apresentações de que tratava o art. $7^{\circ}$ da Lei n. 10.742, de 6 de outubro de 2003. (Alterada pela Resolução CMED n. 4, de 15 de junho de 2005, publicada no DOU 7 de outubro de 2005);

Resolução n. 3, de 5 de março de 2004 - As novas apresentações de medicamentos reconhecidas pelo Comitê Técnico-Executivo como similares às constantes da lista anexa à Resolução n. 5, de 9 de outubro de 2003, ficaram igualmente liberadas dos critérios de ajuste ou estabelecimento de Preço Fábrica, de que tratava o inciso IV do art. 6ํㅡ da Lei n. 10.742, de 6 de outubro de 2003.

\section{5}

Resolução n. 3, de 15 de junho de 2005 - Aprovou, na forma do Anexo a esta Resolução, as alterações no Regimento Interno da Câmara de Regulação do Mercado de Medicamentos - CMED, anexo à Resolução CMED n. 3, de 29 de julho de 2003;

Resolução n. 4, de 15 de junho de 2005 - Aprovou, na forma do Anexo a esta Resolução, as alterações no Anexo da Resolução CMED n. 2, de 5 de março de 2004, que dispunha sobre os critérios para definição de preços de produtos novos e novas apresentações, de que tratava 0 art. $7^{\circ}$ da Lei $n$. 10.742, de 6 de outubro de 2003.

Atualmente, obedecemos ao disposto na Resolução n. 2, de 5 de março de 2004 e na Resolução n. 4, de 15 de junho de 2005 para a formalidade denominada petição junto à CMED para a solicitação de registro de preço. Dessa forma, os produtos deverão ser classificados nas seguintes categorias:

Categoria I: Produto novo com molécula que seja objeto de patente no país e que traga ganho para o tratamento em relação aos medicamentos já utilizados para a mesma indicação terapêutica.

Categoria II: Produto novo que não se enquadre na definição do inciso anterior.

Categoria III: Nova apresentação de medicamento já comercializado pela própria empresa, em uma mesma forma farmacêutica.

Categoria IV: Nova apresentação de medicamento que se enquadre em uma das seguintes situações:

a) medicamento que seja novo na lista dos comercializados pela empresa, à exceção dos casos previstos no inciso III deste artigo;

b) medicamento já comercializado pela empresa, em nova forma farmacêutica.

Categoria V: Medicamento que se enquadrar em uma das seguintes situações:

a) nova forma farmacêutica no país;

b) nova associação de princípios ativos já existentes no país. 
Categoria VI: Medicamento classificado como genérico, de acordo com a redação dada pela Lei n. 9.787, de 10 de fevereiro de 1999 e pelo inciso XXI do art. 3o, da Lei n. 6.360, de 23 de setembro de 1976.

Vale destacar, todavia, que as classificações de categoria determinadas pela CMED nem sempre condizem com a classificação do registro do produto na ANVISA.

Caso a opção de classificação do produto pela empresa na enquadre nas categorias I, II ou V, o documento informativo deverá conter os seguintes elementos:

I. nome de marca do medicamento no Brasil e os demais nomes de marca para o mesmo, utilizados nos países mencionados no inciso VII deste parágrafo e no país de origem do fabricante;

II. número do registro do medicamento e código EAN, ambos compostos de treze dígitos;

III. substâncias a partir das quais o medicamento é formulado;

IV. cópia da bula do medicamento;

V. forma de apresentação em que o medicamento será comercializado;

VI. o preço pelo qual a empresa pretende comercializar cada apresentação, com a discriminação dos impostos incidentes e das margens de comercialização;

VII. preço fabricante, acompanhado da devida comprovação da fonte, praticado na Austrália, Canadá, Espanha, Estados Unidos da América, França, Grécia, Itália, Nova Zelândia, Portugal e o preço fabricante praticado no país de origem do produto, excluídos os impostos incidentes;

VIII. nome do fabricante e local de fabricação do princípio ativo e do medicamento acabado;

IX - número potencial de pacientes a ser tratado com o medicamento, com a indicação do período correspondente.

$X$. análise comparativa de custo-eficácia entre o medicamento e as alternativas terapêuticas existentes;

$X I$. apresentação das seguintes informações referentes à patente do produto: a) Número do primeiro depósito internacional da patente, data do depósito e país em que foi feito; b) Número do depósito da patente no INPI e c) Inovação apresentada pelo produto em que foi baseada a solicitação da patente.

XII. quando disponíveis, apresentação de estudos publicados de avaliação econômica. 
XIII - ensaios clínicos de fase III realizados, que sejam relevantes para a comparação entre o novo medicamento e aqueles existentes no País para a mesma indicação terapêutica, se houver; $e$

XIV - novas indicações terapêuticas para o mesmo medicamento, em estudo, em curso de aprovação ou aprovadas em outros países, se houver.

A lista de países determinada pela CMED possui uma política de preços diferenciados, ou seja, em alguns desses países, os medicamentos prescritos para consumo são parcialmente cobertos pelo sistema público, além disso, há que se considerar a política econômica do país e os impostos incidentes no preço dos medicamentos.

A experiência internacional deve ser considerada por países como o Brasil na definição de suas políticas de medicamentos, com o devido cuidado para não perder de vista as especificidades dos mercados farmacêuticos locais, as necessidades da população, os objetivos sanitários específicos, os objetivos mais amplos das políticas públicas e os recursos disponíveis.

Caso a opção de classificação do produto pela empresa tenha sido a Categoria III, IV ou VI, o documento informativo deverá conter as seguintes informações:

I. nome de marca do medicamento no Brasil e os demais nomes de marca para o mesmo, utilizados nos países mencionados no inciso VII deste parágrafo e no país de origem do fabricante;

II. número do registro do medicamento e código EAN, ambos compostos de treze dígitos;

III. substâncias a partir das quais o medicamento é formulado;

IV. cópia da bula do medicamento;

$V$. forma de apresentação em que o medicamento será comercializado;

VI. o preço pelo qual a empresa pretende comercializar cada apresentação, com a discriminação dos impostos incidentes e das margens de comercialização;

Lembrando que no caso da Categoria VI o Preço Fábrica permitido para o produto classificado na Categoria VI não poderá ser superior a $65 \%$ do preço do medicamento de referência correspondente.

A questão dos medicamentos no Brasil apresenta grandes diferenças em relação aos países desenvolvidos, todavia verificamos que a regulamentação brasileira é muito semelhante à dos países acima mencionados, como veremos adiante.

Somos um país de dimensões continentais, com cerca de 170 milhões de habitantes (2003/2005), distribuídos em 8,5 milhões de km², com grandes 
diferenças regionais, renda concentrada e sem recursos públicos suficientes para a adoção de uma política de assistência farmacêutica de caráter universal.

As especificidades do caso brasileiro tornam as políticas de regulação cruciais à garantia do acesso da população a medicamentos de boa qualidade com preços razoáveis.

$\mathrm{Na}$ definição das políticas nacionais, a experiência internacional tem contribuições importantes a dar, desde que adaptadas para a realidade brasileira.

Não se trata de reproduzir aqui de forma crítica o que tem trazido resultados positivos em outros países, mas de aprender com os erros e os acertos dos que vêm há anos aperfeiçoando instrumentos de regulação.

A experiência de outros países, além de indicar que a questão dos medicamentos não pode ficar ao sabor da livre força de mercado, onde predomina a concorrência imperfeita, demonstra também que não existem soluções únicas nem simplistas para os problemas de saúde pública, principalmente aqueles relacionados exclusivamente com políticas de controle mediante simples tabelamento de preço.

\section{RESULTADO}

A comparação Internacional dos Preços de Produtos Farmacêuticos, conforme os Resultados do Levantamento IMS Health ${ }^{(4)}$ : Dados sem ajustes

Os gráficos abaixo apresentam os preços unitários de medicamentos, em dólares norte-americanos, conforme levantamento do IMS: incluindo impostos (IVA). O Brasil ocupa a sexta posição dentre os países com os menores preços; sem os impostos, seríamos o quinto país.

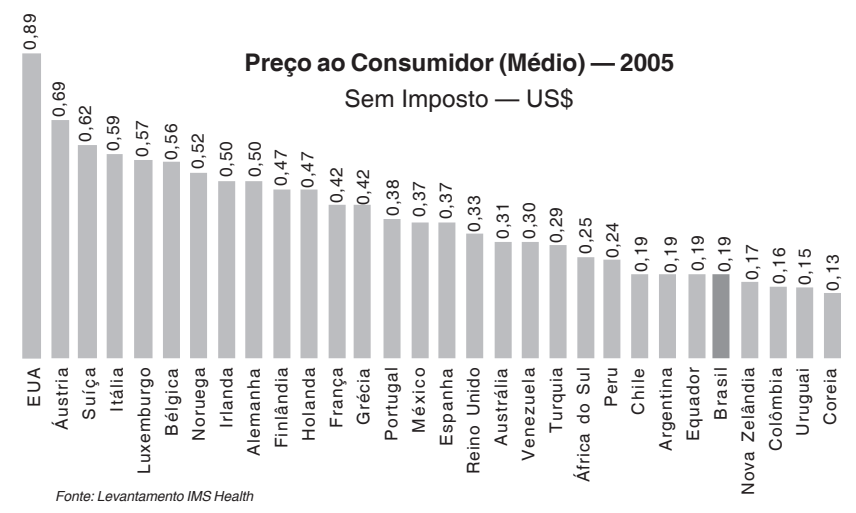

(4) IMS Health. 


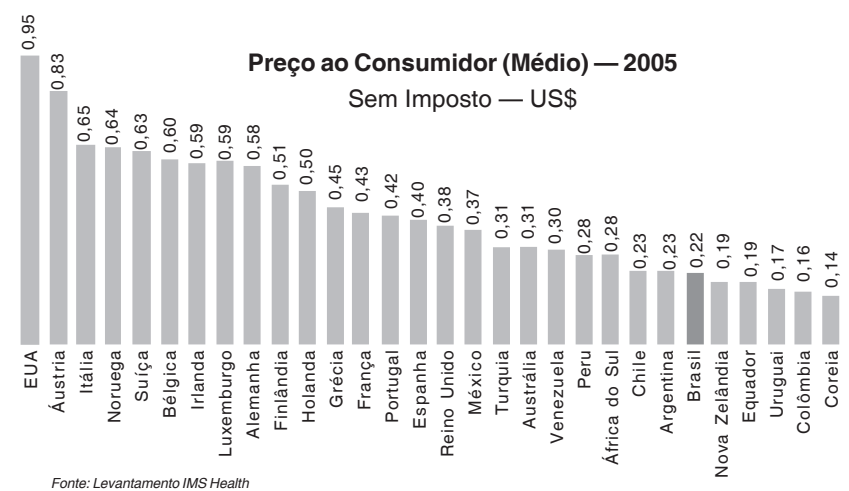

\section{Resultado agregado: o preço brasileiro comparado ao preço mundial médio - Dado sem ajuste}

O IMS calcula a relação entre o preço nacional das unidades padrão, em cada apresentação, e a média mundial do preço de cada uma. Desse conjunto de relação, calcula-se a média, entendida como a posição do valor nacional em proporção ao mundial.

\section{Medicamentos: Preço Médio Nacional em Relação ao Preço Médio Mundial Preço-Fábrica sem IVA}

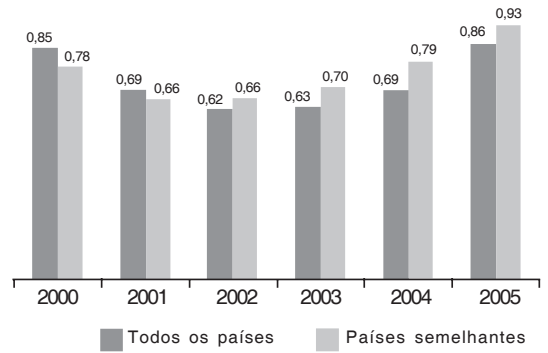


Medicamentos: Preço Médio Nacional em Relação ao Preço Médio Mundial Preço-Fábrica sem IVA

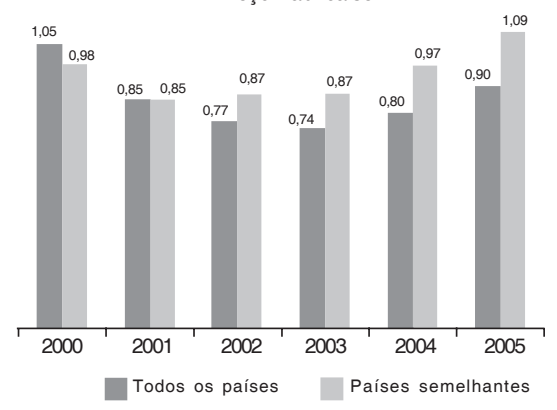

Os dados levantados pelo IMS mostram que no Brasil, o preço dos medicamentos ao consumidor sem IVA, aumentou 26,7\% entre 2005 e 2004 (de US\$ 0,15 para US\$ 0,19), quando medido em dólares. Da mesma forma, a posição relativa do preço médio ao consumidor, comparado à média mundial, foi elevado em 10 pontos percentuais (de $80 \%$ para $90 \%$, conforme o gráfico acima).

Importante assinalar que esses resultados não podem ser comparados de maneira intertemporal, porque a composição amostral muda de ano para ano, refletindo as alterações na cesta de consumo. Em paralelo, embora a forma correta de se avaliar no âmbito internacional seja pela taxa de câmbio de mercado, a leitura do preço nacional para efeito do consumidor doméstico não deve sofrer influência da variação da moeda estrangeira. A valorização do real implica o barateamento de todos os produtos comercializáveis.

Assim, para acompanhar a evolução intertemporal do preço brasileiro, são necessários a estruturação de uma amostra constante e o controle do efeito cambial, entre 2004 e 2005. A amostra que se aproxima da característica desejada é aquela que inclui os produtos presentes em pelo menos 20 países. A correção cambial segue a variação nominal das taxas que serviram de base para a conversão do IMS $^{(5)}$.

\section{COMPARAÇÃO INTERNACIONAL COM AJUSTES}

Observamos duas distorções: o impacto da variação cambial e a composição amostral.

(5) A construção ideal de uma subamostra incluiria um conjunto fixo de produtos vendidos em todos os países. Este procedimento reduz o tamanho das amostras a ponto de troná-las irrelevantes. 
O motivo para se ajustar a flutuação cambial decorre das variações expressivas do dólar.

A reorganização da amostra, para incluir somente os produtos vendidos em pelo menos 20 países, tem por objetivo dar sentido à comparação intertemporal dos preços. A indústria farmacêutica é intensiva em tecnologia, portanto a inovação que implica a alteração permanente na cesta de consumo é um processo natural. Uma nova amostra (ou subamostra) visa a excluir, em parte, o impacto da modernização na tendência dos preços ${ }^{(6)}$.

A análise, inicialmente, subtrai o efeito cambial sobre os resultados da amostra IMS completa. Daí resulta uma nova distribuição internacional de preços (ao câmbio de 2004).

Podemos afirmar que o efeito cambial de 2005 sobre a distribuição internacional dos preços, fez com que o preço médio do medicamento no Brasil fosse o segundo mais barato do planeta, perdendo apenas para a Coreia.

A correção cambial resulta a seguinte distribuição:

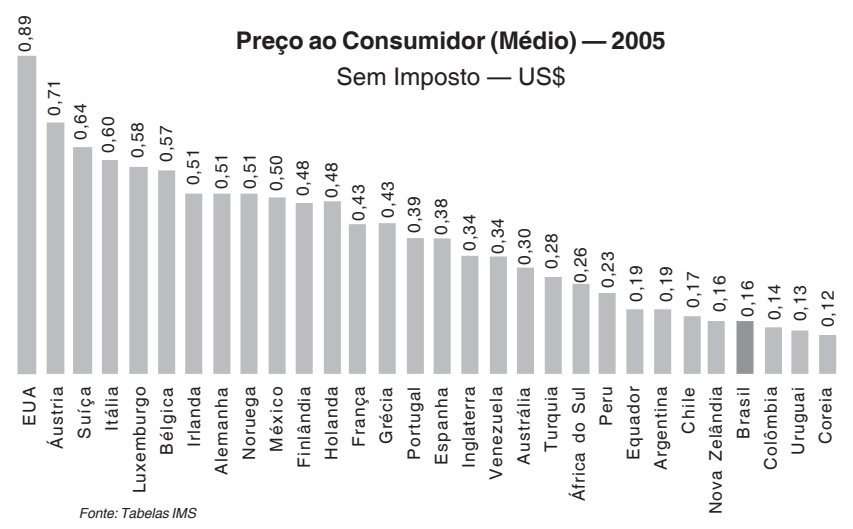

Com a correção, o Brasil passa a se o quarto país com menores preços ${ }^{(7)}$

(6) O encarecimento de um medicamento deve ser sempre analisado mediante a escala preço-eficácia para o tratamento. Um produto mais moderno, cujo preço específico seja superior ao do menos moderno, pode representar o barateamento de tratamento da patologia. De fato, o redesenho da amostra tenta excluir os mais modernos da lista, porque a pesquisa de comparação internacional só permite ver o preço do produto, não o preço do tratamento.

(7) OHANA, Eduardo Felipe. Comparativo internacional de preços de produtos farmacêuticos em 2005. São Paulo: Febrafarma, 2005. 


\section{DISCUSSÃO}

Lembramos que com relação às características estruturais da indústria farmacêutica e seu impacto na política de medicamentos, desde a década de 70 este segmento é composto principalmente por grandes empresas, cuja competitividade está alicerçada em: pesquisa e desenvolvimento ( $P \& D)$, marketing e sistema de patentes.

Dessa forma, podemos dizer que: $P$ \& D, marketing e sistema de patentes formam os três alicerces para o crescimento de uma indústria farmacêutica, vez que o departamento de $\mathrm{P} \& \mathrm{D}$ visa garantir o portfólio da empresa com a segurança da proteção patentária e o marketing juntamente com a área comercial serão responsáveis pelo lançamento e divulgação do produto no ponto de venda e para a classe médica ${ }^{(8)}$.

É importante saber que uma inovação tecnológica, via de regra, somente é patenteável quando representa novidade (se em nível nacional ou internacional, dependendo da política de patentes de cada país), quando implica atividade inventiva e tem aplicação industrial.

Como o primeiro requisito (novidade) não é atendido pelo conceito da inovação incremental, a grande maioria dos lançamentos feitos pela indústria estão sem a respectiva proteção patentária(9).

Para se ter uma ideia, a inovação incremental não patenteável representa $90 \%$ do desenvolvimento nos países de primeiro mundo aumentando ainda mais esse percentual nos países em desenvolvimento.

Sendo assim, graças à expiração das patentes de princípio ativo nos últimos anos, o mercado tem passado por rápidas transformações, acarretando a entrada de medicamentos genéricos e o aumento dos custos com $P$ \& $D^{(10)}$.

Após um breve relato sobre as características estruturais de indústria farmacêuticas, passamos para o impacto causado depois da criação da CMED e suas regulamentações.

A confusão surge porque os agentes reguladores entendem que o preço de qualquer produto deva ser proporcional à renda de cada país.

A Resolução n. 2 da CMED, de março de 2004, é explícita quanto a este entendimento.

(8) KOTLER, Philip. Administração de marketing. 10. ed. São Paulo: Pretince Hall, 2000.

(9) Instituto Nacional da Propriedade Industrial - INPI.

(10) A aceleração dos custos com P \& D nos anos 80 é atribuída a fatores como redução do estoque total de descobertas e mudanças estruturais nos métodos de pesquisa [JACOBZONE, S. Pharmaceutical policies in OECD countries: reconciling social and industrial goals. OECD, 2000. (Occasional Papers, 40)]. 
Um eventual desvio de preço, com sinal de repressão, significa simplesmente um desequilíbrio em relação à estrutura vigente no âmbito internacional.

Ainda que não houvesse regulamentação de preços em um país, seu preço relativo poderia estar reprimido, bastando que houvesse uma mudança estrutural nas demandas domésticas de outros países.

A medição do impacto da regulamentação dos preços dos medicamentos deve levar em consideração a renda e o custo do produto para que os preços internacionais sejam utilizados como referência.

Cabe ressaltar que a repressão regulatória não acompanha o nível de renda como, de fato, deveria.

Os medicamentos são produtos sociais e politicamente sensíveis, motivo pelo qual quase todos os países exercem algum tipo de controle sobre seus preços. Quando um país avalia a efetividade da utilização de controles dos preços, considera também os potenciais impactos negativos: Menor qualidade de produto e restrição de acesso a novos medicamentos (limitação de oferta).

Essa restrição de acesso se faz sentir mesmo em países desenvolvidos. Estudos recentes apontam que o tempo médio para lançamento de um medicamento no mercado norte-americano - onde o controle se faz tão somente por meio das compras efetuadas pelo governo e pelos planos de saúde - é de apenas quatro meses, enquanto que na França - país com maior controle — os lançamentos ocorrem após 15 meses.

Os governos utilizam diversos mecanismos para controle de preços dos medicamentos, que se dividem em três tipos: a) controle de preço; b) mecanismo de reembolso; e c) controle de volume ${ }^{(11)}$.

Uma vez estabelecido o preço para um novo medicamento pelo governo, este passa a funcionar como patamar máximo para os preços a serem negociados; dessa forma, não há dúvida de que os preços dos medicamentos devem ser preocupação e objeto central de políticos, por meio de um conjunto de medidas que possam garantir o acesso de todas as classes sociais ao seu consumo.

Tanto no Brasil como em países desenvolvidos, que, embora adotem, de forma geral, políticas liberais e de desregulamentação interferem de diversas maneiras na produção e na comercialização de medicamentos.

Com efeito, os Estados Unidos, Austrália, Inglaterra, França, Itália, Canadá, Rússia, Japão, China e Holanda, dentre outros, exercem algum tipo de controle de regulamentação de preço com variação de forma e intensidade de um país para outro, objetivando o acesso a medicamentos pela população.

11) SILVA, Rodrigo Alberto Correia da. Controle de preço de medicamento. Estudos Febrafarma, São Paulo, v. 2, 2004. 
O Estado surge para monopolizar o uso da força, por meio de seu poder de polícia e para defender os cidadãos, sendo a Administração Pública responsável por criar e fazer cumprir as normas que dão forma ao próprio Estado.

Sendo assim temos que o Direito e a economia estão intimamente ligados na medida em que são objetos culturais interdependentes e necessários para o equilíbrio da vida em sociedade.

No Brasil, a nossa atual Constituição admite a planificação das atividades relacionadas à prestação de serviços públicos por conta da adesão ao contrato pelos particulares que prestam esses serviços públicos, garantindo a livre concorrência.

A regulação deverá ser sempre realizada com a observância dos objetivos de ampliação ao acesso aos medicamentos pela população.

A ANVISA é o órgão responsável pela segurança e eficácia dos medicamentos no mercado nacional, enquanto que a CMED deveria regulamentar os preços visando ao aceso pela população, todavia com observância e respeito aos custos que a indústria farmacêutica dispende para o seu desenvolvimento e produção.

A inobservância dessa equação resulta na ausência de lançamento de novos produtos inviabilizando o acesso da população a novos medicamentos de controle e combate às suas patologias.

Necessário, ainda, o fomento da assistência farmacêutica por parte dos planos de saúde, seguradoras e gestores de saúde, por meio de normas de incentivo sugeridas pela própria CMED (como ocorre em alguns países, por exemplo, nos Estados Unidos).

O controle de preços como medida unitária, apesar de importante, não se mostra suficiente e eficaz para mudar positivamente o cenário do acesso ao medicamento pela população como pretendido.

O art. 196 da Constituição Federal prescreve que: "O direito à saúde é garantido mediante políticas públicas, sociais e econômicas, que visem à redução do risco de doenças e outros agravos, assegurando, ainda, o acesso universal e igualitário às ações e serviços para sua promoção, proteção e recuperação" e o art. 197 determina que: "São de relevância pública as ações e serviços de saúde, cabendo ao Poder Público dispor nos termos da lei, sobre sua regulamentação, fiscalização e controle."(12)

(12) BRASIL. Constituição Federal de 1988. 


\section{CONSIDERAÇÕES FINAIS}

A regulamentação econômica dos produtos farmacêuticos pode causar impacto considerável ao acesso de medicamentos, contudo questões relativas ao acesso propriamente dito não foram objeto de apreciação neste trabalho, mas sim uma observação referente ao impacto da ação do agente regulador.

Podemos afirmar que no histórico da saúde pública nunca a questão dos medicamentos e da necessidade de se promoverem ações efetivas capazes de viabilizar a expansão do acesso da população aos medicamentos esteve tão presente na agenda do governo.

Este tema, desde 1948, alcança a Organização Mundial da Saúde (OMS) que vem enfatizando a necessidade de ações relacionadas ao acesso a medicamentos, em nível nacional, com quatro objetivos centrais: formular e implementar as políticas de medicamentos; assegurar o acesso da população; comercializar produtos com qualidade e segurança; e promover o uso racional de medicamentos.

Cabe ressaltar que um terço da população mundial não tem acesso aos medicamentos essenciais nas regiões mais pobres do globo, onde cerca de 40 milhões de pessoas morrem anualmente (por infecção respiratória aguda, doença diarreica, tuberculose ou malária) por afecções para as quais se conta com medicamentos eficazes e seguros ${ }^{(13)}$.

O controle de preços na sua forma pura já fracassou ou foi abolido em países que o adotavam, como por exemplo a Inglaterra, que aboliu a Price Commission ${ }^{(14)}$ em 1980, depois de 10 anos de atuação, que deixou como legado um atraso de investimentos na indústria farmacêutica inglesa e um consequente atraso tecnológico.

Neste sentido, observamos que a melhor atuação estatal deveria ser mais no sentido de coibir práticas anticompetitivas do que simplesmente controlar preços, a propósito, conforme opinião do doutrinador Antonio Fonseca(15).

Foi exatamente esta a atitude do governo inglês quando aboliu a Price Commission, que preferiu criar um ambiente de modo a aumentar o número de empresas no setor farmacêutico, como por exemplo a abertura de linhas de créditos subsidiadas para a fabricação de medicamentos de alto consumo e a compra garantida da produção dessas empresas pelo governo, com preços previamente estipulados de modo a induzir ou não a entrada de novas empresas no setor.

(13) BERMUDEZ, Jorge. Remédios: saúde ou indústria? A produção de medicamentos no Brasil. Rio de Janeiro: Relume-Dumará, 1992.

(14) WHISH, Richard. Competition Law. 3 ed. Butterworths. p. 96.

(15) FONSECA, Antônio. Limiting intellectual property. The Competition Interface. University of London, 1994. p. 232. 
Ainda que em vários países o controle de preços já tenha sido abolido, o Brasil continua ditando regras que nem sempre condizem com a nossa realidade.

A justificativa do governo para o controle de preços é o fato da indústria farmacêutica se dirigir a um mercado especial.

A significativa concentração de oferta por grupos terapêuticos, a inelasticidade da demanda ao aumento de preços, o sistema de proteção por patentes, a assimetria de informações e a essencialidade do produto para o consumidor, que não pode dispor da própria saúde, numa situação em que só lhe resta a opção de adquirir o produto, conferem à indústria de medicamentos enorme poder de fixação de preços, fato que gera três ordens de consequências:

a) redução do poder aquisitivo dos consumidores que possuem renda;

b) a inviabilização do exercício de direitos e garantias individuais e sociais que Ihes são fundamentais em relação aos consumidores que não possuem renda, pelo menos de forma suficiente, e

c) aumento de gastos do Governo com o SUS.

A regulação de preços não pode ser a única alternativa como parte de uma política de medicamentos no contexto atual, além do mais, algumas iniciativas de outros países para regulação de preços são perfeitamente aplicáveis no Brasil.

Apesar de ser observada uma melhoria dos processos de aquisição governamental, merece ser destacado, que no Brasil as compras institucionais têm pequena, ou quase nenhuma influência, na formação dos preços dos medicamentos, apesar do grande potencial representado pelo SUS.

Os preços são apenas indicadores de mercado, refletindo o que ocorre, seja no lado da procura, seja no lado da oferta. No entanto, o panorama atual da indústria e o mercado farmacêutico nacional possuem características peculiares que necessitam de uma análise mais profunda para a tomada de decisões na política de medicamentos. Desse modo, entendemos que a CMED é um importante marco regulatório, que não poderia restringir-se à mera edição de tabelas de preços.

Acredita-se que o foco da CMED ou de outro órgão deva ser o de combater práticas anticoncorrenciais e estimular a entrada de mais empresas no setor, mediante políticas afirmativas e de apoio à indústria nacional, principalmente às pequenas empresas.

Sendo assim concluímos que o controle de preço de medicamento representa um verdadeiro retrocesso.

Segundo um artigo publicado na revista do Instituto Brasileiro de Estudos de Concorrência, Consumo e Comércio Internacional (Ibrac) em 2002, que 
relata uma breve história da defesa da concorrência no Brasil, observamos que hoje a estabilidade econômica é tratada pela sociedade brasileira como um patrimônio do qual ela não está disposta a abrir mão(16).

Vale dizer que, no Brasil (como nos demais países da América Latina), prega-se o controle de preços como política econômica, o que já há muito não acontece em países desenvolvidos.

Infelizmente, a criação das agências reguladoras não foi feita no tempo adequado nem com todas as suas normas plenamente estabelecidas, onde idealmente, haveria um conselho interministerial que traçaria, em nome do governo, as políticas para o setor, cabendo à agência sua implementação.

Um aspecto crucial a ser mencionado é que falta nas agências uma área especializada na defesa da concorrência, que pudesse dar ao aparato regulatório um claro direcionamento competitivo(17).

O Brasil é o quinto país dentre aqueles com medicamentos mais baratos, no que se refere ao preço médio ao consumidor sem tributo, entretanto, em contrapartida, ocupa o terceiro posto na escala de repressão de preços.

Podemos afirmar que a edição de normas inadequadas, ou a interferência inoportuna, além de dificultar o acesso aos medicamentos não resolve a questão da sua falta, agravando ainda mais o problema, acirrando as próprias desigualdades e falhas do mercado, além do mais, afugenta os agentes econômicos levando consigo os investimentos e deixa a população mais carente de medicamentos, concluindo que a regulação malfeita é ainda pior que a ausência de regulação.

\section{REFERÊNCIAS BIBLIOGRÁFICAS}

BERMUDEZ, Jorge. Remédios: saúde ou indústria? A produção de medicamentos no Brasil. Rio de Janeiro: Relume-Dumará, 1992.

CONSIDERA, C. M. Uma breve história da economia política da defesa da concorrência. Revista do Ibrac, v. 9, n. 5. 2002.

FONSECA, Antônio. Limites jurídicos da regulação e defesa da concorrência. Porto Alegre: S.A. Fabris, 2003

Limiting intellectual property. The Competition Interface. University of London, 1994.

GRAU, Robert E. A Ordem Econômica na Constituição de 1988. 8. ed. São Paulo: Malheiros Ed., 2003.

(16) CONSIDERA, C. M. Uma breve história da economia política da defesa da concorrência. Revista do Ibrac, v. 9, n. 5.

(17) FONSECA, Antônio. Limites Jurídicos da Regulação e Defesa da Concorrência. Porto Alegre:

S.A. Fabris, 2003. 
JACOBZONE, S. Pharmaceutical policies in OECD countries: reconciling social and industrial goals. OECD, 2000 (Occasional Papers, 40).

KOTLER, Philip. Administração de marketing. 10. ed. São Paulo: Pretince Hall, 2000.

OHANA, Eduardo Felipe. Comparativo internacional de preços de produtos farmacêuticos em 2005. São Paulo: Febrafarma, 2005.

SANCHEZ, C. G. Aspectos da relação entre Estado e iniciativa privada: enfoque constitucional 1999. 120f. Dissertação (Mestrado em Direito Constitucional) - Faculdade de Direito, Pontifícia Universidade Católica, São Paulo, 1999.

SILVA, Américo L.M. da. Ordem constitucional econômica. Rio de Janeiro: Lúmen Júris, 1996.

SILVA, Rodrigo Alberto Correia da. Controle de preço de medicamento. Estudos Febrafarma, São Paulo, v. 2, 2004.

WHISH, Richard. Competition law. 3. ed. Butterworths, 1995. 